International Journal of Power Electronics and Drive System (IJPEDS)

Vol. 11, No. 4, December 2020, pp. 1816 1825

ISSN: 2088-8694, DOI: 10.11591/ijpeds.v11.i4.pp1816-1825

\title{
Performance evaluation of PI controller for positive output Luo converter
}

\author{
Muhammed Abduljaleel Ibrahim \\ Systems and Control Engineering Department, Ninevah University, Iraq
}

\begin{tabular}{l}
\hline \hline Article Info \\
\hline Article history: \\
Received Apr 5, 2020 \\
Revised Jun 22, 2020 \\
Accepted Jul 9, 2020 \\
\hline
\end{tabular}

Keywords:

Integral square error (ISE).

P/O Luo converter

Particle swarm optimization

(PSO)

PI controllers

\begin{abstract}
The aim of this work is to design and analyze a Proportional Integral (PI) controller for Positive Output Luo Converter applications. Positive Output Luo Converter is a developed DC-DC converter. It is respected as a right choice for most industrial application where the rate of the output load voltage must be varying between the low and high values of the input value of voltage, output voltage rise and fall is smaller. This converter involve Power electronics switches (Diodes and MOSFET) since these elements are non-linear. The detailed model includes high-frequency switching that is introducing discontinuities into the model. PI controller coefficients $(\mathrm{kp}, \mathrm{ki})$ are calculated by particle swarm optimization (PSO) to provide optimal PI as hybrid PI by PSO controller with simple design procedure .Transient and steady state responses requirement of the system are considered in designing the proposed PI controller. The consequences show that the time of performing characteristics of PSO-PI controller established on integral squared error (ISE) performance index has the best time performing characteristics, line disturbance, load disturbance and set point variation.
\end{abstract}

This is an open access article under the CC BY-SA license.

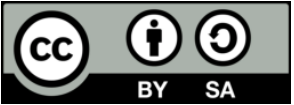

\section{Corresponding Author:}

Muhammed Abduljaleel Ibrahim

Systems and Control Engineering Department,

Ninevah University, Mosul/ Iraq.

Email: muhammed.ibrahim@uoninevah.edu.iq

\section{INTRODUCTION}

Power electronics is the equipment of managing and utilizing the flow of electric power by delivering voltages and currents in a type that is optimally enhanced to the end-user conditions that shown in atypical block diagram in Figure 1 [1-4].Conversation DC/DC techniques are more important researches for power electronics filed [5]. DC/DC converters was found from twenties of last century and developed quickly. The simplest one is voltage divider, now many DC/DC converters used in industrial application like electric vehicles, power supply systems and lighting systems. By simple configuration, Luo converter has low voltage ripple and has high voltage gain with high power density [1]. DC/DC converters have fixed input and variable output. Buck and Boost converters used to DC voltage regulation but they regulate the output voltage with limit gain, the operating theories, small signal developing, and differences with other converters are showed [6]. Positive output super lift converter is one of transformer less DC/DC converters used to obtain high output voltage. These series Luo converters will be useful in industrial applications [7]. According to [8] the researcher used super lift Luo converter as a drive for DC motor. The DC motor speed control is based on fuzzy logic and PI controllers, intend and MATLAB software simulation of a positive output Super Lift (SL) Luo converter is investigated. The operation of three special converters such as Luo converter, ZETA converter and Single-Ended Primary-Inductance Converter (SEPIC) has been analyzed. The Input-Output parameters, switching losses, fall and rise voltage and efficiency are evaluated [9]. As [10] 
states that the proposed $\mathrm{P} / \mathrm{O}$ Luo converter to use in electrical cars with a topology reduce the output ripple by reducing total harmonics distortion (THD) with high power density, the major purpose is to achieve the high efficiency and minimal constructions.

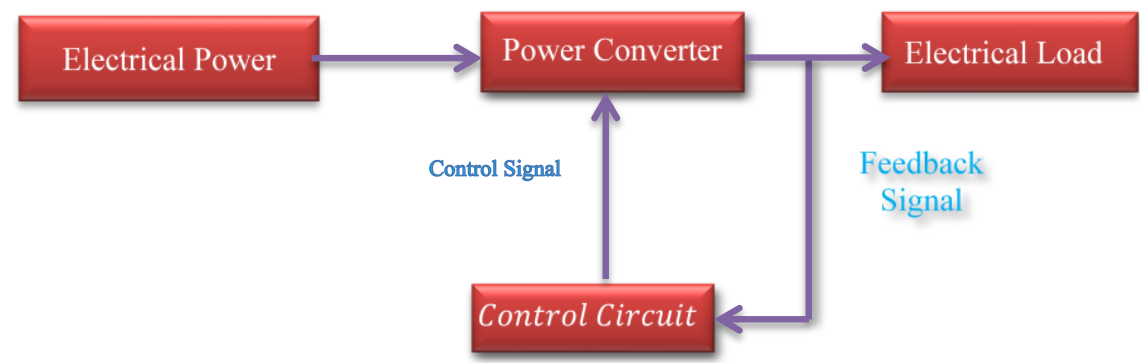

Figure 1. Power electronic system block diagram [11]

Proposes topology to overcome stresses on PO Lou device by zero voltage switching (ZVS-PWM) by using antiparallel diode and resonant capacitor and inductor which represent a tank circuit in switching device. Bridgeless-Luo (BL-Luo) converter is a recommended solution for brushless DC (BLDC) motor drive control system. A power factor correction (PFC) constructed BL-Luo converter supplied BLDC motor has been envisioned for wide range of speeds and decreased switching damages [12]. Self lift positive output P/O Luo DC-DC converter employing Incremental Conductance (IncCond) algorithm for photovoltaic drives. The IncCond algorithm is used to track the maximum power of the solar panel. It is also utuilizes to measure the maximum power obtained from the photovoltaic (PV) by varying the duty cycle in the positive output self-lift Luo converter [13].Modified particle swarm optimization (PSO) is presented to improve the tracking speed in addition to occurrence, the results of the intended MPPT in the PV array are in comparison with the conventional PSO system. After comparing, the tracking speed of MPPT and efficiency is enhanced [14].

Positive Output Luo Converter is important DC/DC converter. Considerally significant in electrical circuit equipment. Effectively used in DC/DC converter appliances. In this work, proposed PI controller tuned by Particle Swarm Optimization (PSO) to get more benefit from Positive Output Luo Converter which is used to control output load voltage when variations occurs on load, DC voltage supply and set point tracking. The PSO algorithm adjusts the PI coefficients $(k p, k i)$ by diminishing the selected performance index (Integral Square Error (ISE) and Integral Absolute Error (IAE).

\section{RESEARCH METHOD}

Positive Output Lou Converter is shown in Figure 2, has Battery as voltage source (Vin),Power Switch(S), the inductors as passive storage elements (L1, L2), freewheeling diode (D) and two capacitors $(\mathrm{C} 1, \mathrm{C} 2)$ to transfer energy form the supply to the load by mean inductors[1, 15]. During storing and transferring the energy from source to load, the voltage variation above capacitor average voltage neglected, therefore the $\mathrm{V} \_\mathrm{c}(\mathrm{t}) \cong \mathrm{V} \_\mathrm{c}$.

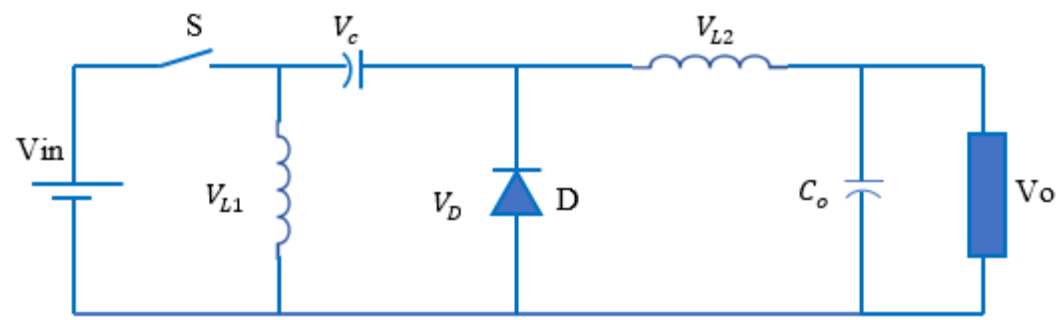

Figure 2. The circuit diagram of the positive output Luo converter

Positive Output Lou converter Operation Mode, there are two operation mode for P/O luo converter which is[10] : 
Mode 1: When switch (S) closed (on state) as shown in Figure 3 source current $I_{S}$ pass through $L_{1}$ and $L_{2}$, will be summation of $I_{L 1}$ and $I_{L 2}\left(L_{1}\right.$ and $L_{2}$ absorb energy)

$I_{S}=I_{L 1}+I_{L 2}$

Free wheeling diode is reverse bias and the inductance $L_{1}$ suck and store the energy form the source and the capacitor. The current $I_{L 1}$ and $I_{L 2}$ increase.

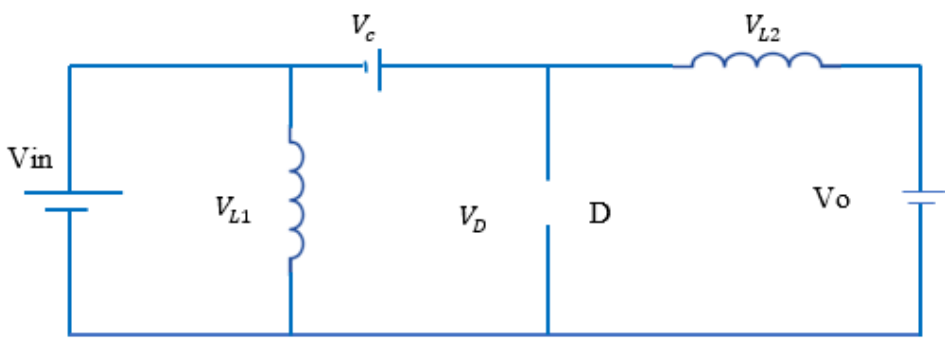

Figure 3. Mode 1 operation (switch-on)

Mode 2: when switch (S) is open (off state) as shown in Figure 4, the source current $I_{S}$ is zero and inductor $L_{1}$ transfer stored energy to capacitor $C$ through free wheeling diode. Regarding to inductor $\left(L_{2}\right)$, the inductor current $I_{L 2}$ pass through the capacitor and load and free wheeling diode in order to maintain the continuity. The current $I_{L 1}$ and $I_{L 2}$ decrease

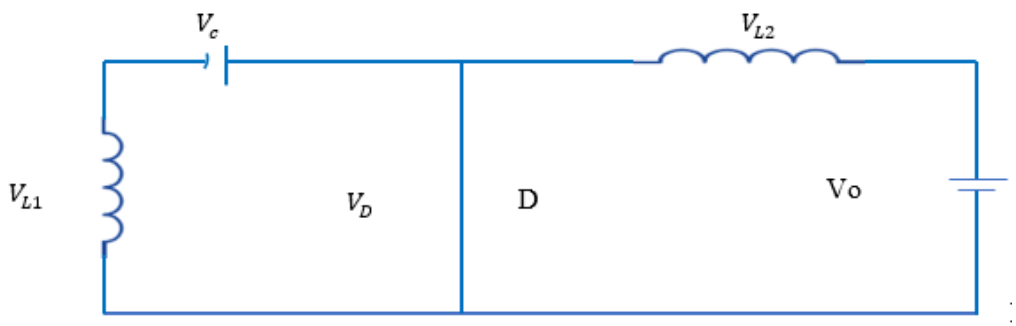

Figure 4.Mode 2 operation (switch off)

These equations represent the characteristics of the converter to obtain the voltage transfer gain.

During opened switch (off state), Capacitor (C) charge is:

$Q=(1-k) T I_{l 1}$

During closed switch (on state), Capacitor (C) charge is:

$-Q=K T I_{l 2}$

From above equations, the current inductor $\left(L_{2}\right)$ can be calculated by:

$I_{l 2}=\frac{1-k}{k} I_{l 1}$

The capacitor $(\mathrm{Co})$ is used as low pass filter (LPF) therefore output current $\left(I_{o}\right)$ is:

$I_{o}=I_{l 2}$

The average source current $I_{\text {in }}$ :

$I_{\text {in }}=K I_{S}=K\left(I_{L 1}+I_{L 2}\right)=K\left(1+\frac{1-k}{k}\right) I_{L 1}=I_{L 1}$ 
Consequently, the output current be present

$I_{o}=\frac{1-k}{k} I_{\text {in }}$

Also the output voltage is

$$
V_{o}=\frac{K}{1-k} V_{i n}
$$

The voltage transfer gain of positive output luo DC-DC converter in continuous conduction mode is

$$
M_{E}=\frac{k}{1-k}
$$

The parameters for positive output luo converter that utilized in this paper showed in Table 1 [16].

Table 1 Converter circuit parameter

\begin{tabular}{ccc}
\hline Parameters & Symbol & The Value \\
\hline Supply Voltage & Vin & $12 \mathrm{~V}$ \\
Output Voltage & Vo & $12 \mathrm{~V}$ \\
Switching frequency & Fs & $50 \mathrm{KHz}$ \\
Inductors & L1 ,L2 & $100 \mu \mathrm{H}$ \\
Capacitors & C1, $\mathrm{C} 2$ & $10 \mu \mathrm{F}$ \\
Load Current & Io & $1.2 \mathrm{~A}$ \\
\hline
\end{tabular}

\section{CONTROL APPROACH}

Control performs a major function in automation and complex industrial processes. PI controllers have been operated in manufacturing development control appliances. The influence of their extensive acceptance lies in the ease of design and appropriate performance involving minimal overshoot and insignificant settling time $[17,18]$. The PI control is intended to confirm the requiring requested nominal operating point for P/O Luo converter. For the sudden disturbances, set point variations. The configuration of the PI controller with PSO algorithms for closed loop control system is shown in Figure 5.

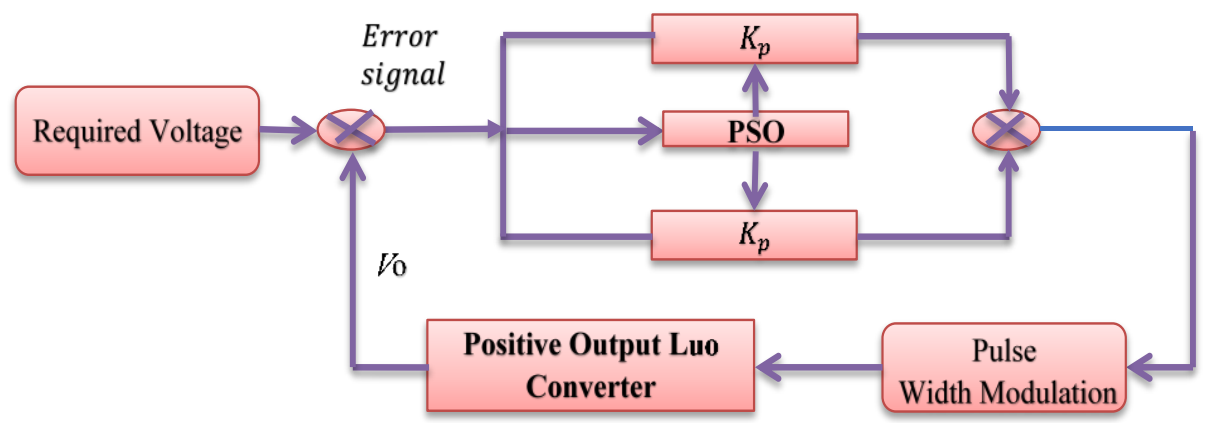

Figure.5. Closed loop control system configuration of positive output Luo converter

Consider the PI controller law of the form [19, 20].

$$
u(t)=K_{p} * e(t)+K_{i} \int e(t)
$$

Where: $u(t)$; control signal output,e(t); error signal, $k_{p}$; proportional factorand $k_{i}$; integral factor.The positive output Luo converter is modeled using power electronics switch (MOSFETs) that cannot be linearized for linear PI controller system design. The important point to consider in the PI controller design for the positive output Luo converter is how to calculate controller coefficients (kp, ki). In order to locate the optimal PI controller parameters particle swarm optimization (PSO) is utilized to design PI controller coefficients in the proposed work. 


\subsection{PI controller design based on particle swarm optimization}

Particle swarm optimization approach firstly developed by Kennedy and Eberhart in 1995 as one of the global optimization techniques [21]. PSO is programmed on the swarm intellect concept and impersonators the collective performances of simple agents that are nearby interconnecting with their situation [22]. PSO algorithm is effective in resolving difficult non-convex problems and multimodal problems, which is cause of its productive purpose in many areas of science and engineering [23].

It was stimulated by the social performance of the bird and fish schooling and has been attained to be robust in resolving nonlinear complex optimization difficulties [21]. The PSO algorithm is launched with initialization, after that the revise of velocity and position, fitness computation, the best position and convergence examination are updated [24]. The PSO algorithms are applied to search its globally optimal gains (kp, ki) for PI controller. Integral absolute - error criterion (IAE) and Integral Square - error (ISE) is chosen as performance index in the controller approach procedure [25].

The performance index (IAE, ISE) expressions are as follows [25, 26].

$$
\begin{aligned}
& I A E=\int_{0}^{T s s} a b s[e(t)] d t \\
& \text { ISE }=\int_{0}^{T s s}[\mathrm{e}(\mathrm{t})]^{2} \mathrm{dt}
\end{aligned}
$$

There are two members for each particle in PSO algorithms that are kp and ki. In other words, the search space has two spaces and the particles are moving according to the two-dimensional spac. To enhance and locate optimal values that get best performance for the proposed circuit [21]. The optimization program is employed by MATLAB computer software/script program and connected with the system model program in MATLAB/SIMULINK. The major factors of the PSO algorithm (the number of particles, the number of generations, initial rate of the global-best factor, span of the initial population, the initial velocity span, absolute cost of the individual best factor, absolute value of the global-best factor, initial value of the individual best Factor) are selected by the designer of the algorithm and the problem to be resolved [23, 27, 28]. The procedures tracked by the intended PSO algorithm for positive output luo converter to attune the PI controller coefficients are summarized in in Figure. 6.

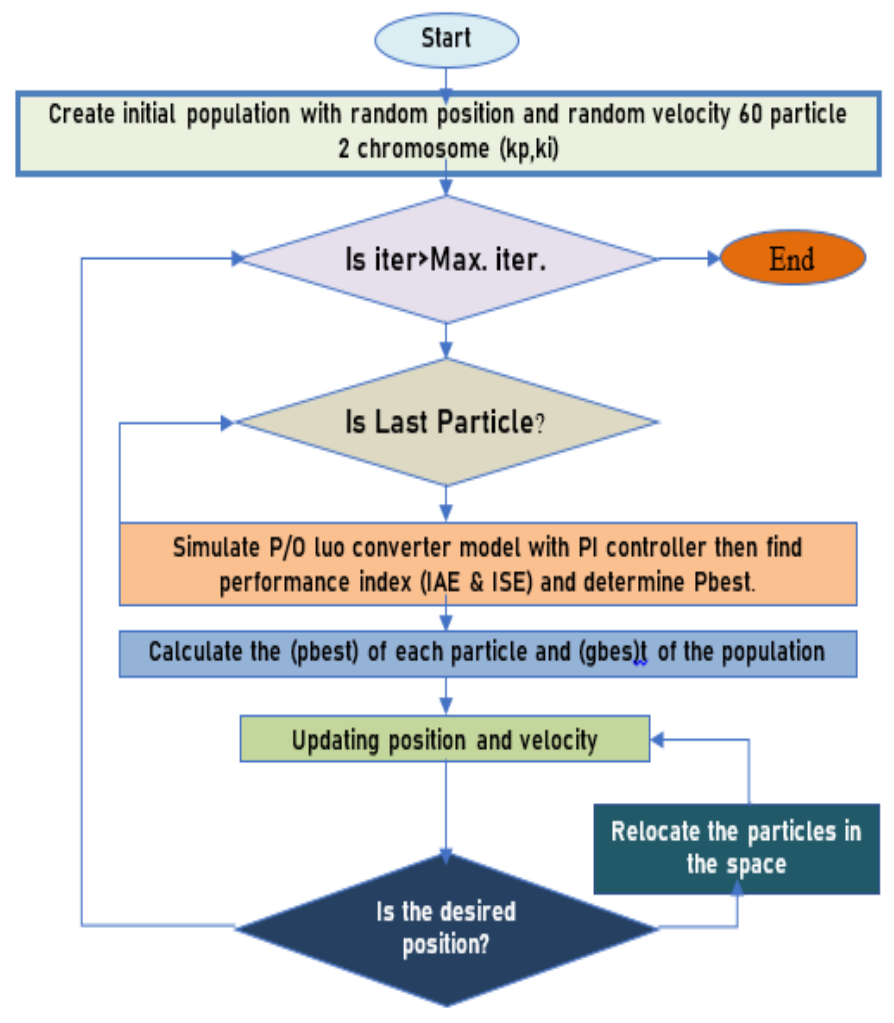

Figure 6. The flowchart of PSO-PI control system design procedure 


\section{RESULTS AND DISCUSSION}

This portion considers the closed loop control system of proposed positive output Luo converter utilizing MATLAB/SIMULINK computer software. The system is also used to investigate the circuit in numerous operative scenarios. Figure 7 presents the closed loop system simulation circuit of the positive output Luo converter. The output load voltage is detected and evaluated with the set point voltage. The resultant error voltage signal is fed as an input to PI controller to produce suitable duty cycle (k) for power switch(S) according to system operation conditions.

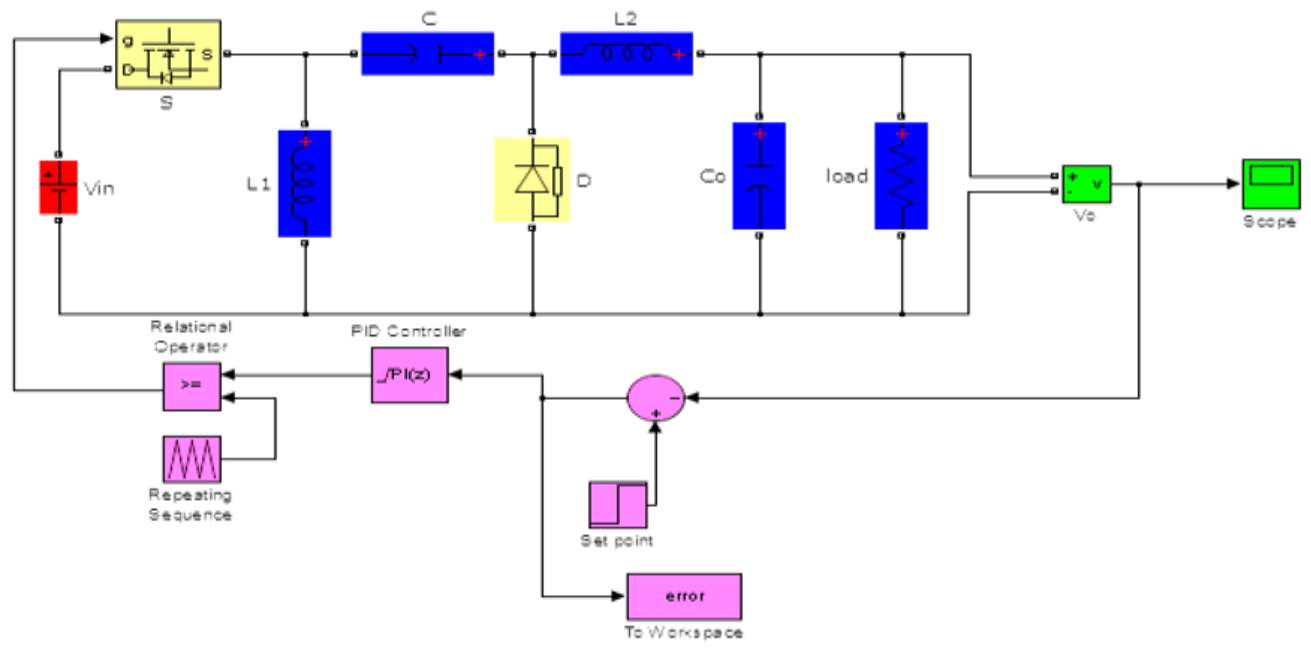

Figure 7. Simulink model of the positive output Luo converter with PI controller.

The proposed methodology is executed in MATLAB language. The proof of the system performance is done for four special situations, namely, the startup transient, line variation, load variation and time response characteristics. Figure $8 \& 9$ shows the simulation results for startup transient in buck mode (9v set point) and boost mode (15 V set pint).

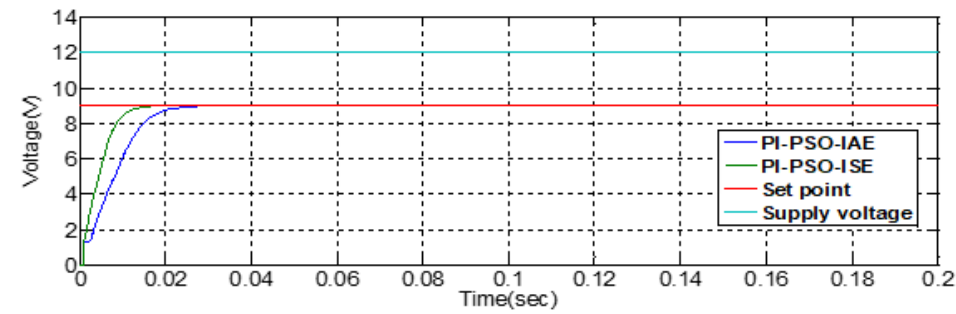

Figure 8. The response of positive output Luo converter when the input DC voltage $12 \mathrm{~V}$ and set point $9 \mathrm{~V}$ (buck mode).

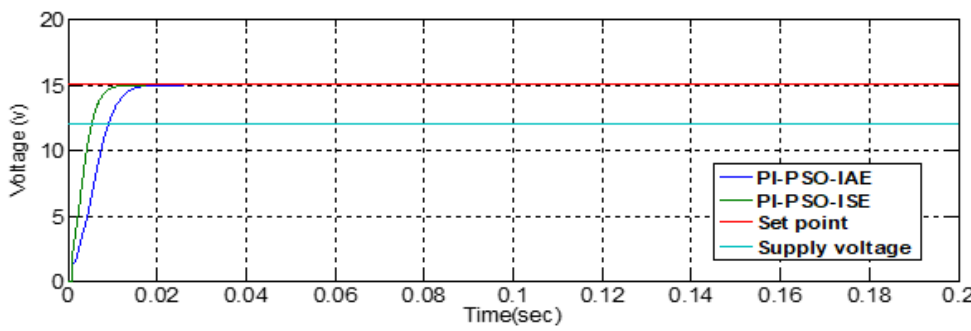

Figure 9. The response of positive output Luo converter when the input DC voltage $12 \mathrm{~V}$ and set point $15 \mathrm{~V}$ (boost mode). 
In set point tracking test Figure 10, shows the load voltage track the reference at constant input voltage $12 \mathrm{~V}$.At $\mathrm{t}=0.1 \mathrm{~S}$ the set point voltage change from $14 \mathrm{~V}$ to $10 \mathrm{~V}$. Figure 11 , shows load voltage track the reference at $\mathrm{t}=0 . .1 \mathrm{~S}$ set point voltage change from $10 \mathrm{~V}$ to $14 \mathrm{~V}$. Result show the actual load voltage follows the set point voltage command.

Figure $12 \& 13$ shows the P/O luo converter with PI controller under line regulation. when supply voltage variation occurs at $\mathrm{t}=0.1 \mathrm{~S}$. with test in two cases stepping-up and stepping down in supply voltage.

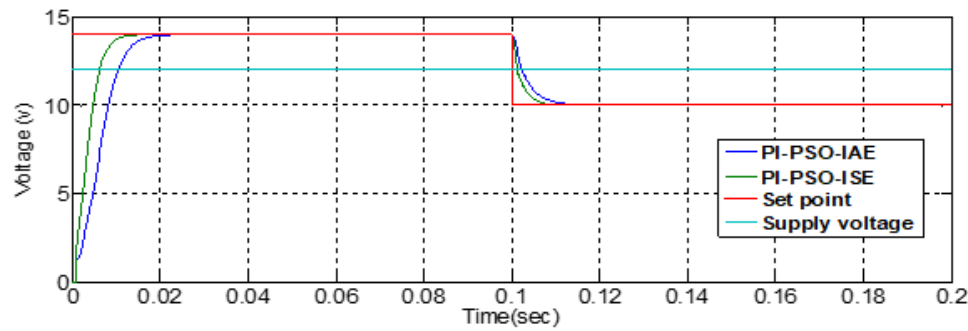

Figure 10. The response of positive output Luo converter when the input DC voltage $12 \mathrm{~V}$ and set point voltage command change from $14-10 \mathrm{~V}$.

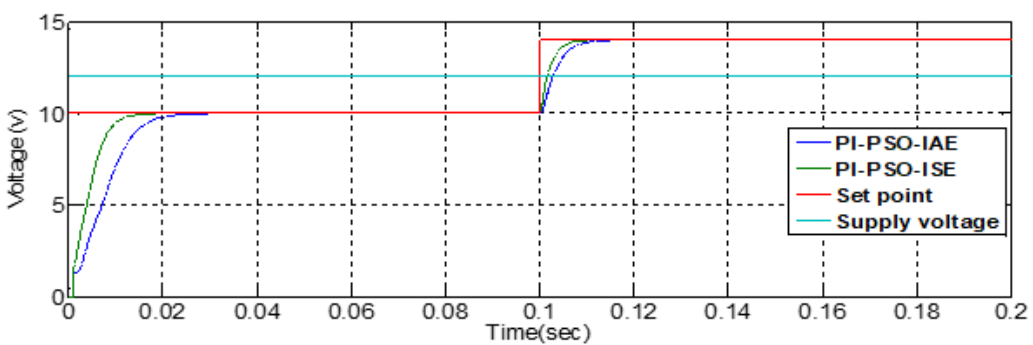

Figure 11. The response of positive output Luo converter when the input DC voltage $12 \mathrm{~V}$ and set point voltage command change from $10-14 \mathrm{~V}$.

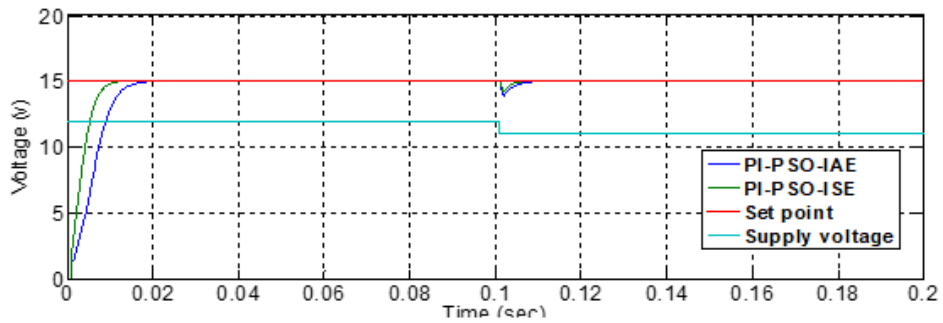

Figure 12. Line regulation of positive output Luo converter (step change of supply voltage from $12-11 \mathrm{~V}$ at $\mathrm{t}=0.1 \mathrm{~S})$

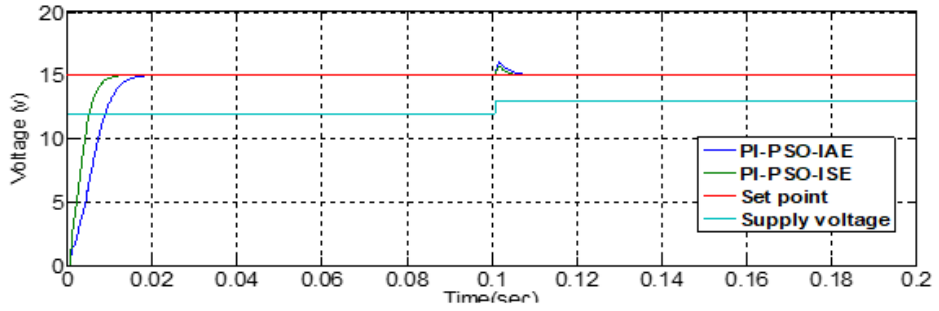

Figure 13. Line regulation of positive output luo converter (step change of supply voltage from $12-13 \mathrm{~V}$ at $\mathrm{t}=0.1 \mathrm{~S})$ 
Figure 14 and 15 shows the output load voltage of positive output Luo converter with load variation conditions when it subject to disturbance in load current. The deviation of output load voltage with the disturbance in load current (load disturbance) could be investigated, there is a slight overshoot and steady state is attained with a very less time.

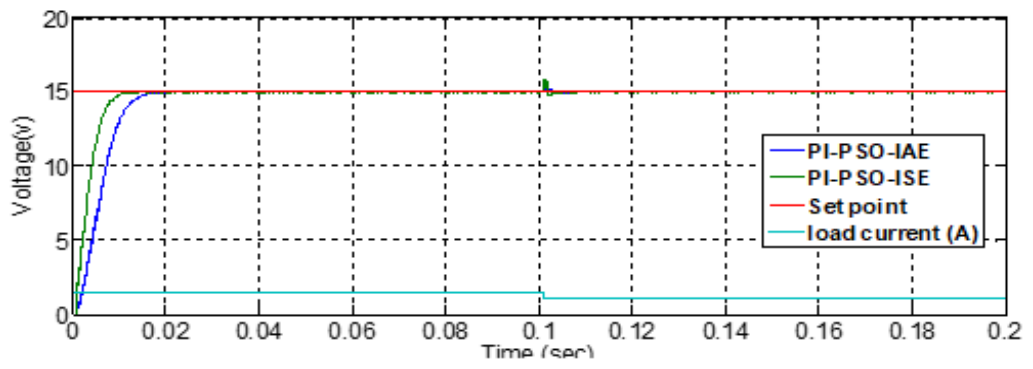

Figure 14. Load regulation of positive output Luo converter (stepping down of load current at $\mathrm{t}=0.1 \mathrm{~S}$ )

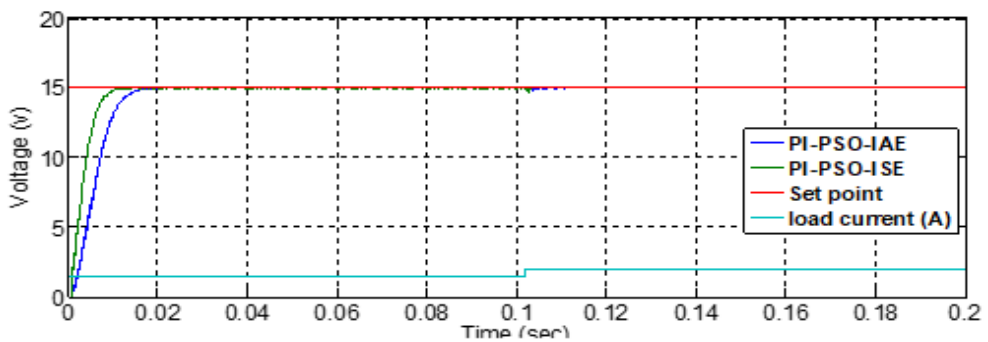

Figure 15. Load regulation of positive output Luo converter (stepping-up of load current at $\mathrm{t}=0.1 \mathrm{~S}$ )

The compared value of time response characteristics (peak over shoot, rise time and settling time) are shown in Figure 16. According the consequences in Figure 16, the rise time and settling time of PI-PSOISE method is better results than the rise rime and settling time of PI-PSO-IAE method.

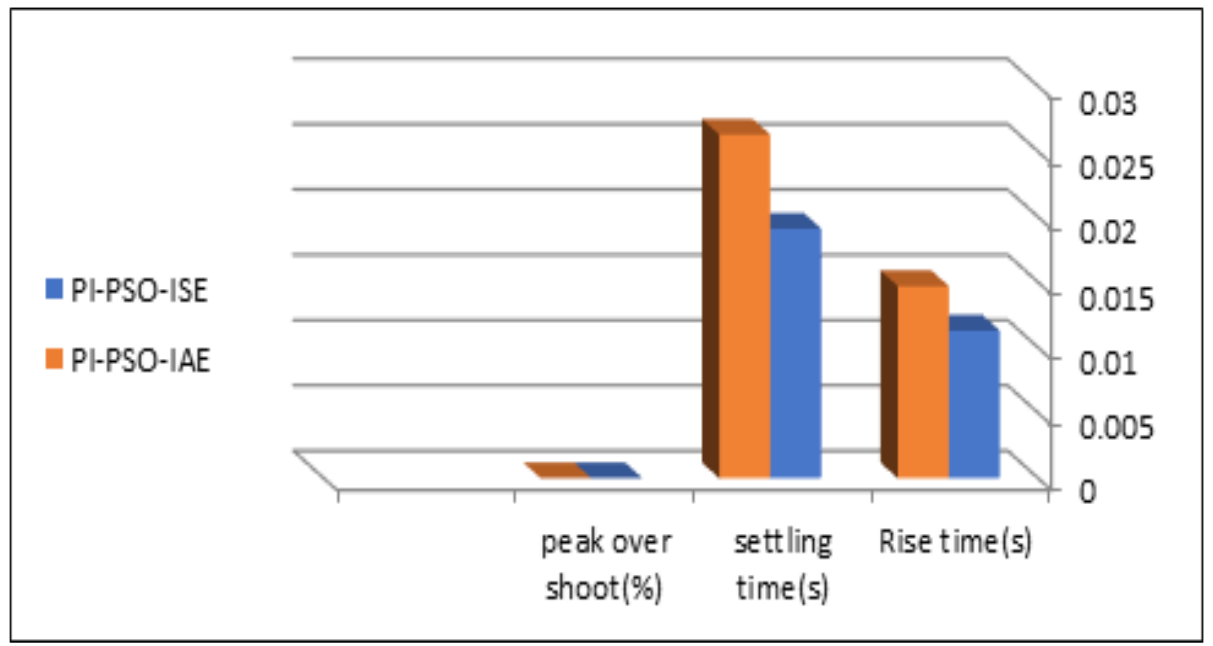

Figure 16. Statistical clarification of time response characteristics

From the performance investigation for all cases test study, The P/O luo converter with PI controller has a satisfactory response and can be benefitted in many industrialized applications such as, computer peripheral apparatus, HEV-Hybrid Electric Vehicle, tramway and railway electrification. 


\section{CONCLUSION}

$\mathrm{P} / \mathrm{O}$ Luo Converter can be utilized in medical apparatus, computer board circuits and engineering applications. Control of this type of DC - DC converter plays a main role in automation and complex industrial processes. The Simulation results demonstrates that the suggested PI controller adjusts acceptable output voltage of $\mathrm{P} / \mathrm{O}$ Luo Converter regardless of line disturbances, load disturbances and set point variation. The controller gains are calculated by optimizing the costing signal by the PSO algorithm. The proposed controller shows a significant reduction in difference between input signal command and actual output voltage. Simulation results shows that the control system approach is stable with an acceptable time response characteristics. Accordingly this proposed controller can be utilized to industrial responsive uses. In the future different intelligent approaches can be used to design PI controller and select the best controller performance of them.

\section{REFERENCES}

[1] Luo, Fang Lin, and Hong Ye., "Power electronics: advanced conversion technologies," CRC press, 2018.

[2] Luo, Fang Lin, "Double-output Luo converters, an advanced voltage-lift technique," IEE proceedings-electric power applications, vol.147, no. 6, pp. 469-485, 2000.

[3] Luo, Fang Lin, and Hong Ye, "Advanced multi-quadrant operation DC/DC converters," CRC Press, 2018.

[4] Khather, Salam Ibrahim, and Muhammed A. Ibrahim, "Modeling and simulation of SEPIC controlled converter using PID controller," International Journal of Power Electronics and Drive Systems (IJPEDS), vol. 11, no. 2, pp. 833, 2020.

[5] Dhamodharan, S., et al., "An improved luo converter for high power applications," International Journal of research in engineering and technology, pp. 2319-1163, 2014.

[6] Miao, Shan, Faqiang Wang, and Xikui Ma, "A new transformerless buck-boost converter with positive output voltage," IEEE Transactions on Industrial Electronics, vol. 63, no. 5, pp. 2965-2975, 2016.

[7] Luo, Fang Lin, and Hong Ye, "ositive output super-lift converters," IEEE Transactions on Power Electronics, vol. 18, no. 1, pp. 105-113, 2003.

[8] Baghramian, Alfred, and Hasan Ghorbani Eshyani, "Fuzzy Controller of luo converter for controlling of DC motors speed," 4th Annual International Power Electronics, Drive Systems and Technologies Conference. IEEE, 2013.

[9] Siddharthan, Niranjana, and Baskaran Balasubramanian, "Performance evaluation of SEPIC, Luo and ZETA converter," International Journal of Power Electronics and Drive Systems (IJPEDS), vol. 10, no. 1, pp. 374, 2019.

[10] Manikandan, A., and N. Vadivel, "Design and implementation of luo converter for electric vehicle applications," International Journal of Engineering Trends and Technology (IJETT), vol. 4, no. 10, pp. 4437-4441, 2013.

[11] Bright, S. J. V., S. Ramkumar, and H. Anand, "Positive output elementary Luo converter for fixed-frequency ZVS operation," Bulletin of the Polish Academy of Sciences Technical Sciences, vol. 65, no. 2, pp. 255-262, 2017.

[12] Singh, Praveen Kumar, et al., "BLDC motor drive based on bridgeless landsman PFC converter with single sensor and reduced stress on power devices," IEEE Transactions on Industry Applications, vol. 54, no. 1, pp. 625-635, 2017.

[13] Chilambarasan, M., M. Latha Devi, and M. Ramesh Babu, "Design and Simulation of Self Lift Positive Output Luo Converter Using Incremental Conductance Algorithm for Photovoltaic Applications," Applied Mechanics and Materials, vol. 622, 2014.

[14] Yoganandini A. P, Anitha G. S., "A modified particle swarm optimization algorithm to enhance MPPT in the PV array," International Journal of Electrical and Computer Engineering, vol. 10, no. 5, pp. 5001-5008, 2020.

[15] Luo, Fang Lin, and Hong Ye, "Mathematical modeling of power DC/DC converters," 2004 International Conference on Power System Technology, PowerCon 2004, vol. 1, 2004.

[16] Kiran, Nagulapati, "Control of Chaos in Positive Output Luo Converter by means of Time Delay Feedback," International Electrical Engineering Journal (IEEJ), vol. 6, no.2, pp. 1787-1791, 2015.

[17] Luo, Fang Lin, and Hong Ye, "Positive output multiple-lift push-pull switched-capacitor Luo-converters," IEEE transactions on industrial electronics, vol. 51, no.3, pp. 594-602, 2004.

[18] Yilmaz, Unal, Ali Kircay, and Selim Borekci, "PV system fuzzy logic MPPT method and PI control as a charge controller," Renewable and Sustainable Energy Reviews, vol. 81, pp. 994-1001, 2018.

[19] Burns, Roland, “Advanced control engineering," Elsevier, 2001.

[20] Perry, Alexander G., et al., "A design method for PI-like fuzzy logic controllers for DC-DC converter," IEEE transactions on industrial electronics, vol. 54, no.5, pp. 2688-2696, 2007.

[21] Sultan, N. S., and A. H. Ahmad, "Hybrid Fuzzy Logic Based a Particle Swarm Optimization Controller Design for ZETA Converter," AL Rafdain Engineering Journal, vol. 22, no.4, pp. 88-99, 2014.

[22] Siano, Pierluigi, and Costantino Citro, "Designing fuzzy logic controllers for DC-DC converters using multiobjective particle swarm optimization," Electric Power Systems Research, vol. 112, pp. 74-83, 2014.

[23] Bošković, Marko, Milan Rapaić, and Zoran Jeličić, "Particle swarm optimization of pid controller under constraints on performance and robustness," International Journal of Electrical Engineering and Computing, vol. 2, no.1, pp. 1-10, 2018.

[24] Kamari, N. A. M., et al., "Intelligent swarm-based optimization technique for oscillatory stability assessment in power system,” IAES International Journal of Artificial Intelligence, vol. 8, no.4, 2019. 
[25] S Dawood, Younis, Ali K Mahmood, and Muhammed A Ibrahim, "Comparison of PID, GA and Fuzzy Logic Controllers for Cruise Control System," International Journal of Computing and Digital Systems, vol. 7, no. 5, pp. 311-319, 2018.

[26] Ayas, Mustafa Şinasi, and Erdinc Sahin, "Parameter effect analysis of particle swarm optimization algorithm in PID controller design," An International Journal of Optimization and Control: Theories \& Applications (IJOCTA), vol. 9, no.2, pp. 165-175, 2019.

[27] Salman, Ghassan Abdullah, Assama Sahib Jafar, and Ammar Issa Ismael, "Application of artificial intelligence techniques for LFC and AVR systems using PID controller," International Journal of Power Electronics and Drive Systems (IJPEDS), vol. 10, no. 6, pp. 1694-1704, 2019.

[28] Alqadasi, Mohammed Maged Abdullah, et al., "Optimization of PID for industrial electro-hydraulic actuator using PSOGSA," TELKOMNIKA Telecommunication, Computing, Electronics and Control, vol. 17, no. 5, pp. 2625-2635, 2019.

\section{BIOGRAPHY OF AUTHOR}

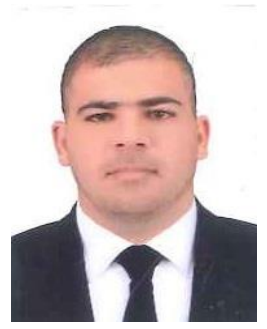

Muhammed A. Ibrahim. B.Sc in Power Technical Engineering/ Northern Technical UniversityIraq-Mosul in 2011 with grade very Good with Ranked first. MSc in Electrical Engineering/Control Engineering from Electrical Eng. Dept. / College of Engineering /University of MosulIn 2013. Currently he is a head of a scientific affairs department / Ninevah University. Current research interests include linear and nonlinear systems optimization, Machines and drives. 